\title{
Hysterosalpingographic evaluation of human immunodeficiency virus-infected and uninfected infertile women
}

\begin{tabular}{|c|c|}
\hline \multicolumn{2}{|c|}{$\begin{array}{l}\text { Authors: } \\
\text { Dolongo C. Onyangunga }{ }^{1} \\
\text { Jagidesa Moodley }\end{array}$} \\
\hline \multicolumn{2}{|c|}{$\begin{array}{l}\text { Affiliations: } \\
\text { 'Department of Radiology, } \\
\text { School of Clinical Medicine, } \\
\text { University of KwaZulu-Natal, } \\
\text { Durban, South Africa }\end{array}$} \\
\hline \multicolumn{2}{|c|}{$\begin{array}{l}\text { Women's Health and HIV } \\
\text { Research Unit, Department } \\
\text { of Obstetrics and } \\
\text { Gynaecology, School of } \\
\text { Clinical Medicine, University } \\
\text { of KwaZulu-Natal, Durban, } \\
\text { South Africa }\end{array}$} \\
\hline \multicolumn{2}{|c|}{$\begin{array}{l}\text { Corresponding author: } \\
\text { Dolongo Onyangunga, } \\
\text { dolongocarine@gmail.com }\end{array}$} \\
\hline \multicolumn{2}{|c|}{ Received: 03 July 2019} \\
\hline \multicolumn{2}{|c|}{$\begin{array}{l}\text { How to cite this article: } \\
\text { Onyangunga DC, Moodley J. } \\
\text { Hysterosalpingographic } \\
\text { evaluation of human } \\
\text { immunodeficiency virus- } \\
\text { infected and uninfected } \\
\text { infertile women. S Afr } \\
\text { J Rad. 2020;24(1), a1767. } \\
\text { https://doi.org/10.4102/sajr. } \\
\text { v24i1.1767 }\end{array}$} \\
\hline \multicolumn{2}{|c|}{$\begin{array}{l}\text { Copyright: } \\
\text { C 2020. The Authors. } \\
\text { Licensee: AOSIS. This work } \\
\text { is licensed under the } \\
\text { Creative Commons } \\
\text { Attribution License. }\end{array}$} \\
\hline \multicolumn{2}{|l|}{ Read online: } \\
\hline 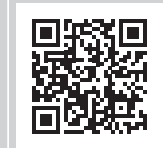 & $\begin{array}{l}\text { Scan this QR } \\
\text { code with your } \\
\text { smart phone or } \\
\text { mobile device } \\
\text { to read online. }\end{array}$ \\
\hline
\end{tabular}

Background: Hysterosalpingography (HSG) is an outpatient fluoroscopy-guided procedure that evaluates the uterine cavity and fallopian tube patency in infertile women. Its costeffective use is being challenged with the human immunodeficiency virus (HIV) burden in KwaZulu-Natal, which characteristically affects multiple organs.

Objectives: The aim of this study was to describe the HSG findings in a group of HIV-infected and uninfected infertile women.

Method: This was a retrospective study conducted over a 4-year period (2012-2016) in which the HSG images and reports of 178 infertile patients from records of the Radiology Department were re-reviewed for abnormalities of the cervix, uterus and fallopian tubes. Their clinical data and radiological findings were entered into a pre-coded data sheet and analysed.

Results: The frequency of HIV infection amongst patients with infertility was found to be $32.6 \%$. Forty-four patients were on antiretroviral therapy at the time of the HSG examination, whereas three had not yet started treatment. From the 178 HSG reports, 109 (61.2\%) were abnormal. Tubal pathologies were the most common abnormalities, accounting for 79 of the 109 cases and was higher in HIV-infected women than in HIV-uninfected women ( $p=0.001)$. Uterine filling defects were demonstrated in 13 of the 109 cases. There were two cases of cervical abnormalities.

Conclusion: The study demonstrated that tubal abnormalities were the most common findings amongst infertile women undergoing HSG and occurred predominantly in HIV-infected patients.

Keywords: hysterosalpingography; infertility; HIV; sexually transmitted diseases; fallopian tubes; radiology.

\section{Introduction}

Infertility is defined as the incapacity of a couple at reproductive age to conceive after regular and unprotected sexual intercourse within 2 years. ${ }^{1}$ It may be classified as primary infertility for a couple who never conceived or secondary infertility when occurring after a previous pregnancy.

Infertility remains a serious health concern with sociocultural implications, particularly in women of African ancestry. ${ }^{2}$ In Africa, 30\% - 40\% of couples present with infertility. ${ }^{3}$ The major cause of infertility in South Africa (SA) is sexually transmitted disease, which leads to genital tract pathology including endometritis and salpingitis, complicated by tubal mucosal damage and blockage. The human immunodeficiency virus (HIV) epidemic in SA over the last three to four decades has compounded the impact of sexually transmitted infections on infertility. ${ }^{4,5,6}$ However, treatment of HIV infection has been reported to reduce infertility rates. ${ }^{7,8}$

A variety of imaging techniques including hysteroscopy, ultrasonography (US), hysterosalpingography (HSG) and pelvic magnetic resonance imaging (MRI) are available to evaluate the patency of the female genital tract for the investigation of infertility. The unavailability of expertise and the costs of imaging techniques, such as MRI and diagnostic laparoscopy, make HSG the most commonly used first-line imaging technique for evaluating female infertility in district and most regional hospitals in SA.

To the best of our knowledge, there are no local reports on HSG findings in HIV-infected women with infertility. This is of importance for the KwaZulu-Natal province, which carries the highest burden of the HIV pandemic, with rates of approximately $37 \%$ in antenatal attendees. ${ }^{9}$ Therefore, the 
aim of this study was to report on HSG findings in a setting of high HIV infection rates.

\section{Methods \\ Study design}

This was a descriptive, retrospective study covering a 4-year period, from 01 January 2012 to 31 December 2016, in the Radiology Department of a Central Hospital in Durban, KwaZulu-Natal. The radiological information system of the hospital was used to obtain the relevant clinical records and imaging findings of patients referred for HSG as part of an infertility work-up during the study period. Each included patient had prior US of the pelvis and laboratory tests for ovulation. Hysterosalpingography was performed according to standard protocols, with the images reviewed by both a gynaecologist and a radiologist. ${ }^{10}$ The final reports were documented by the radiologist. The report and final images were archived in a Radiology Information Database. For the purpose of this study, both the reports and the images were re-reviewed by the author, a registrar in radiology, and by a specialist radiologist with 4 years of experience.

The socio-demographic and clinical information was recorded on a structured data sheet. The documentation of the HIV status was considered absolute criteria for inclusion. We considered the risk factor profile of women with secondary infertility as well. ${ }^{11}$ Women with incomplete clinical information, other proven causes of infertility and a history of tuberculosis or records of anti-tuberculosis treatment were excluded from the study.

All statistical analysis was performed using Statistical Package for the Social Sciences (SPSS version 25, IBM Corp, 2017). The results were expressed as mean and standard deviation. The Z-test was used for the difference between means. A $p$-value of $<0.05$ was considered statistically significant.

\section{Results}

The records of 178 infertile women with complete information who underwent HSGs were retrieved. The mean (standard deviation [s.d.]) age and duration of infertility of the patients were $33.3 \pm 4.7$ years and $5.64 \pm 4.1$ years, respectively. Amongst them, $64.6 \%$ had primary infertility and $35.4 \%$ had secondary infertility. Hysterosalpingography reports were normal in $38.8 \%(69 / 178)$ of patients, whilst the remaining $61.2 \%$ patients $(109 / 178)$ had at least one abnormal HSG finding. Subgroup analysis showed that 120 (67.4\%) women were HIV-uninfected and 58 (32.6\%) were HIV-infected. Forty-four patients were on antiretroviral therapy at the time of HSG examination, whereas three had not yet started treatment. The demographic and clinical profiles of the infertile women are presented in Tables 1 and 2.

Of the 41 women who had previous pelvic surgery, 27 were HIV-uninfected and 14 were HIV-infected. The association with HIV infection was significant $(p=0.047)$. Forty-three
TABLE 1: Demographic and clinical profile of infertile women.

\begin{tabular}{|c|c|c|c|c|c|}
\hline Variable & Mean \pm s.d. & $n$ & $\%$ & Minimum & Maximum \\
\hline Age groups (years) & $33.3 \pm 4.7$ & - & - & 21 & 43 \\
\hline$<25$ & - & 6 & 3.4 & - & - \\
\hline $25-30$ & - & 41 & 23.0 & - & - \\
\hline $31-40$ & - & 124 & 69.7 & - & - \\
\hline$>40$ & - & 7 & 3.9 & - & - \\
\hline Parity groups & $0.56 \pm 0.88$ & - & - & 0 & 3 \\
\hline 0 & - & 115 & 64.6 & - & - \\
\hline 1 & - & 37 & 20.8 & - & - \\
\hline 2 & - & 16 & 9.0 & - & - \\
\hline 3 & - & 10 & 5.6 & - & - \\
\hline \multicolumn{6}{|l|}{ Type of infertility } \\
\hline Primary & - & 115 & 64.6 & - & - \\
\hline Secondary & - & 63 & 35.4 & - & - \\
\hline Duration of infertility (years) & $5.64 \pm 4.1$ & - & - & 1 & 18 \\
\hline \multicolumn{6}{|l|}{ Previous miscarriage } \\
\hline Yes & - & 12 & 6.7 & - & - \\
\hline No & - & 166 & 93.3 & - & - \\
\hline \multicolumn{6}{|l|}{ Previous surgery } \\
\hline Yes & - & 41 & 23.0 & - & - \\
\hline No & - & 137 & 77.0 & - & - \\
\hline \multicolumn{6}{|c|}{ Previous pelvic inflammatory disease } \\
\hline Yes & - & 43 & 24.2 & - & - \\
\hline No & - & 135 & 75.8 & - & - \\
\hline
\end{tabular}

s.d., standard deviation.

TABLE 2: Demographic and clinical profile of infertile women based on human immunodeficiency virus status.

\begin{tabular}{|c|c|c|c|c|c|c|c|}
\hline \multirow[t]{2}{*}{ Variable } & \multicolumn{3}{|c|}{ HIV-infected } & \multicolumn{3}{|c|}{ HIV-uninfected } & \multirow[t]{2}{*}{$p$} \\
\hline & Mean \pm s.d. & $n$ & $\%$ & Mean \pm s.d. & $n$ & $\%$ & \\
\hline \multicolumn{8}{|l|}{ HIV status } \\
\hline CD4 $(n=19)$ & $481.9 \pm 258.3$ & 58 & 32.6 & - & 120 & 67.4 & - \\
\hline \multicolumn{8}{|c|}{ HIV treatment $(n=44)$} \\
\hline FDC & - & 24 & 13.5 & - & - & - & - \\
\hline HAART & - & 20 & 11.2 & - & - & - & - \\
\hline \multicolumn{8}{|l|}{ Type of infertility } \\
\hline Primary & - & 31 & - & - & 84 & - & - \\
\hline Secondary & - & 27 & - & - & 36 & - & - \\
\hline Age groups (years) & $33.4 \pm 5.1$ & - & - & $33.2 \pm 3.7$ & - & - & 0.7 \\
\hline$<25$ & - & 0 & - & - & 6 & - & - \\
\hline $25-30$ & - & 12 & - & - & 29 & - & - \\
\hline $31-40$ & - & 45 & - & - & 79 & - & - \\
\hline$>40$ & - & 1 & - & - & 6 & - & - \\
\hline Parity (groups) & $0.5 \pm 0.87$ & - & - & $0.7 \pm 0.9$ & - & - & 0.07 \\
\hline 0 & - & 31 & - & - & 84 & - & - \\
\hline 1 & - & 14 & - & - & 23 & - & - \\
\hline 2 & - & 11 & - & - & 5 & - & - \\
\hline 3 & - & 2 & - & - & 8 & - & - \\
\hline $\begin{array}{l}\text { Duration of infertility } \\
\text { (years) }\end{array}$ & $5.7 \pm 4.2$ & - & & $5.5 \pm 3.8$ & & & 0.8 \\
\hline Miscarriage & - & 10 & - & - & 2 & - & 0.1 \\
\hline $\begin{array}{l}\text { Pelvic inflammatory } \\
\text { disease }\end{array}$ & - & 24 & - & - & 19 & - & 0.001 \\
\hline
\end{tabular}

HIV, human immunodeficiency virus; FDC, full drug combination; HAART, highly active antiretroviral therapy; $n$, number; s.d., standard deviation; $C D 4$, cluster of differentiation4.

(24.2\%) women provided a history of pelvic inflammatory disease (PID) and 24 (55.81\%) of those were HIV-infected. Pelvic inflammatory disease and HIV were also significantly associated $(p=0.001)$.

Sixty-three patients presented with secondary infertility before undergoing HSG. Previous caesarean delivery was performed in 29 of these patients presenting with uterine and/or tubal 
abnormalities at HSG. Human immunodeficiency virus infection was more frequent in the caesarean delivery group than in the vaginal delivery group $(p=0.000)$.

Tubal pathologies were the most common abnormalities and accounted for $79 / 109$ (72.5\%) of the abnormal findings. They presented as bilateral occlusions or unilateral tubal occlusions with hydrosalpinx. The next most common abnormality was seen in the uterine cavity, with 13 filling defects. The majority (14) of filling defects were confirmed on pelvic US as air bubbles and not considered as a pathology; 10 were submucosal fibroids and three were congenital uterine malformations. There was one uterine synechia. Cervical pathologies included elongated cervix and stenosed cervix, where the procedure was then abandoned.

Ten HIV-infected patients (17.2\%) had more than one documented cause of infertility. Tubal pathologies were the only cause of infertility that was significantly associated with HIV infection $(p=0.001)$. The HSG findings are presented in Table 3

\section{Discussion}

The main findings of this study showed that a substantial proportion of patients who had HSGs were HIV-infected (32.6\%). The study confirmed a smaller number of HIVinfected infertile women $<25$ years old and a larger proportion between 25 and 40 years of age. Although infertility affects all reproductive ages, it was also not documented in any HIV-uninfected patients less than 25 years of age. In a similar study conducted by Heis et al., ${ }^{12}$ the overall mean age was 31.5 years (s.d. 5.9 years), with maximum occurrence at 18-46 years and a mean (s.d.) infertility duration of $4 \pm 3.4$ years. Panti ${ }^{13}$ reported a mean age of $28.9 \pm 6.5$ years and a mean duration of infertility of $7.47 \pm 1.6$ years. Chen and Walker ${ }^{14}$ reported that the agespecific fertility rates of HIV-infected women are reduced as compared to uninfected women, except for those in the

TABLE 3: Hysterosalpingography findings.

\begin{tabular}{|c|c|c|c|c|c|c|}
\hline \multirow[t]{2}{*}{ Abnormalities } & \multirow[t]{2}{*}{$\begin{array}{c}\text { Total } \\
(n=178)\end{array}$} & \multicolumn{2}{|c|}{$\begin{array}{l}\text { HIV-infected } \\
\quad(n=58)\end{array}$} & \multicolumn{2}{|c|}{$\begin{array}{l}\text { HIV-uninfected } \\
\quad(n=120)\end{array}$} & \multirow[t]{2}{*}{$p$} \\
\hline & & $n$ & $\%$ & $n$ & $\%$ & \\
\hline \multicolumn{7}{|l|}{ Cervix $(n=2)$} \\
\hline Elongated cervix & 1 & 1 & 1.7 & 0 & 0 & - \\
\hline Stenosed cervix & 1 & 1 & 1.7 & 0 & 0 & - \\
\hline \multicolumn{7}{|l|}{ Uterus ( $n=28)$} \\
\hline Filling defect & 13 & 6 & 10.3 & 7 & 5.8 & - \\
\hline Uterine synechiae & 1 & 1 & 1.7 & 0 & 0 & - \\
\hline Air bubbles & 14 & - & - & - & - & - \\
\hline Tubal pathology $(n=79)$ & 79 & 46 & 79.3 & 33 & 28.3 & $0.001 *$ \\
\hline Unilateral hydrosalpinx & 18 & 7 & 12.1 & 11 & 9.2 & 0.5 \\
\hline Bilateral hydrosalpinx & 11 & 8 & 13.8 & 3 & 2.5 & 0.3 \\
\hline Bilateral distal occlusion & 5 & 5 & 8.6 & 0 & 0 & - \\
\hline Unilateral distal occlusion & 15 & 10 & 7.2 & 5 & 4.2 & 0.05 \\
\hline Bilateral proximal occlusion & 8 & 4 & 6.9 & 4 & 3.3 & 0.7 \\
\hline Unilateral proximal occlusion & 14 & 4 & 6.9 & 10 & 8.3 & 0.7 \\
\hline Bilateral proximal/distal occlusion & 4 & 4 & 6.9 & 0 & 0 & - \\
\hline Unilateral proximal/distal occlusion & 4 & 4 & 6.9 & 0 & 0 & - \\
\hline
\end{tabular}

HIV, human immunodeficiency virus.

$*$, significant at $p<0.05$.
15-19 years age range where fertility is said to be higher based on reports from many countries.

In this study, the incidence of primary infertility was higher than that of secondary infertility, which is in accordance with other studies. ${ }^{13,14,15}$ However, contradictory findings where secondary infertility was more common than primary infertility have also been documented. ${ }^{6,16}$ We did not find any significant statistical association between the duration of infertility and HIV.

The frequency of HIV infection in the study was $32.6 \%$. This prevalence rate is much higher than previous reported values from Gabon (9.3\%), ${ }^{17}$ Tanzania $(18.2 \%)^{17}$ and SA $\left.(20 \%)\right)^{18}$ The high rates of HIV are probably because KwaZulu-Natal has the highest HIV burden in SA; the rate amongst antenatal attendees is $37 \%{ }^{8}$

It should be noted that $25 \%$ of the HIV-infected infertile women in this study had not initiated anti-retroviral (ARV) treatment. Although no side effects or adverse events of HSG were noted in the study for both infected and uninfected women, the study was not designed to evaluate the complications in HIV-infected women following HSG. This might be regarded as a limitation of the study. It is plausible that any invasive procedure of the female genital tract in HIV-infected women may cause infective complications. This needs further investigation and it seems intuitive that gynaecologists initiate ARVs prior to any investigations for infertility. We only found one study in the current literature that has evaluated HSG procedures in HIVpatients. ${ }^{19}$

The results of this study revealed that $38.8 \%$ of the patients had normal HSGs; however, our finding is lower than the $49.2 \%$ reported previously in a similar study in Nigeria. ${ }^{8}$ This may be related to the HIV burden in the study sample. Other studies have recorded $16.6 \%$ and $29.1 \%$ of normal findings. ${ }^{13,20,21}$

Tubal factor infertility was seen in $79.3 \%$ of our HIV-infected patients. Some HIV-infected patients $(6.2 \%)$ had more than one documented cause of infertility. Tubal factor was the only cause of infertility that was significantly associated with HIV infection $(p=0.001)$. Yahya et al. ${ }^{7}$ reported tuboperitoneal factor as the most common cause of infertility (seen in $81 \%$ of HIV-infected patients) and the association as statistically significant, with a $p$-value of 0.048. Similarly, Adegoke et al. ${ }^{8}$ reported that tubo-peritoneal abnormalities were more common amongst infertile women infected with HIV as compared to those without HIV infection. Adesiyun et al. $^{4}$ also reported a study on HSG and found that distal tubal occlusion with hydrosalpinx was mainly associated with HIV infection.

\section{Limitations of the study}

There was no follow-up of the patients to monitor any longterm complications related to the procedure. Furthermore, there was no record of the duration or initiation of ARV regimen. Many patients were excluded from the study because of a history of tuberculosis or anti-tuberculosis 
treatment, even though there was a concurrent positive medical history of HIV. It is important to note that the infertile women were investigated without examining their spouses; thus, it could be that their infertility is related to their partners. This is a major limitation of this study.

\section{Conclusion}

This study has shown that HSG remains an important diagnostic tool in the evaluation of the infertile women, particularly in public-sector health facilities in SA, where there is a lack of equipment, technology and expertise. Hysterosalpingograms are cheap, quick and easily accessible. We demonstrated that tubal abnormalities were the most common findings amongst infertile women undergoing HSG, occurring predominantly in HIV-infected patients.

\section{Acknowledgements}

The authors would like to thank Prof. D.P. Ramaema, Head of Radiology Department at Inkosi Albert Luthuli Central Hospital, who gave access to their Data Base System.

\section{Competing interests}

The authors have declared that no competing interests exist.

\section{Authors' contributions}

All authors contributed equally to this work.

\section{Ethical consideration}

Approval for the study was granted by the Bioethics Research Committee (BE: 406/17), University of KwaZulu-Natal, the Postgraduate Education Committee, Hospital management and the KwaZulu-Natal Department of Health.

\section{Funding Information}

This research received no specific grant from any funding agency in the public, commercial or not-for-profit sectors.

\section{Data availability statement}

Data sharing is not applicable to this article as no new data were created or analysed in this study.

\section{Disclaimer}

The views and opinions expressed in this article are those of the authors and do not necessarily reflect the official policy or position of any affiliated agency of the authors.

\section{References}

1. WHO. Reproductive health indicators for global monitoring. Report of the second interagency meeting. WHO/RHR/01.19. Geneva: World Health Organization, Department of Reproductive Health and Research; 2001

2. Mascarenhas MN, Flaxman SR, Boerma T, Vanderpoel S, Stevens GA. National, regional, and global trends in infertility prevalence since 1990: A systematic analysis of 277 health surveys. PLoS Med. 2012;9(12):1001356. https://doi.org/ 10.1371/journal.pmed.1001356

3. Leke RJ, Oduma JA, Bassol-Mayagoitia S, Bacha AM, Grigor KM. Regional and geographical variations in infertility: Effects of environmental, cultural, and socioeconomic factors. Environ Health Perspect. 1993;101(2):73-80. https://doi. org/10.1289/ehp.93101s273

4. Adesiyun AG, Ameh C, Eka A. Hysterosalpingographic tubal abnormalities and HIV infection among black women with tubal infertility in sub-Saharan Africa. Gynecol Obstet Investig. 2008;66(2):119-122. https://doi.org/10.1159/ 000128600

5. Lash MM, Yaghamee A, Strohsnitter W, Lalwani S. Association between secondary infertility and fallopian tube obstruction on hysterosalpingography. J Reprod Med 2008;53(9):677-680.

6. Mazzuca P, Caruso A, Caccuri F. HIV-1 infection, microenvironment and endothelia cell dysfunction. New Microbiol, 2016;39(3):163-173.

7. Yahya A, Adesiyun A, Olorukooba AA. Seroprevalence and clinical correlates of human immunodeficiency virus infection among women with infertility in NorthWestern Nigeria. Trop J Obstet Gynaecol. 2018;35(2):177-183. https://doi.org/ 10.4103/TJOG.TJOG_17_18

8. Adegoke AA, Anthony E, Olumide AB, Folake O, Idowu AA. Hysterosalpingographic tubal abnormalities in retroviral (HIV) positive and negative infertile females. J Clin Diagn Res. 2013;7(1):35-38. https://doi.org/10.7860/JCDR/2012/4938.2664

9. National Department of Health. Saving mothers 2011-2013: Sixth report on confidential enquiries into maternal deaths in South Africa. Fact sheet. Pretoria: National Committee for Confidential Enquiry into Maternal Deaths, Department of Health Republic of South Africa; 2015.

10. Chapman S, Nakielny R. Chapter 6: Aids to radiological procedures. In: Watson N, Jones $\mathrm{H}$, editors. Chapman \& Nakielny's guide to radiology procedures. 4 th ed. London: Elsevier, 2001; p. 175-180.

11. Dhont $N$, Luchters $S$, Muvunyi $C$, et al. The risk factor profile of women with secondary infertility: An unmatched case-control study in Kigali, Rwanda. BMC Womens Health. 2011;11:32. https://doi.org/10.1186/1472-6874-11-32

12. Heis $\mathrm{M}$, Amarin Z, Ibrahim AY, Obeidat N, Obeidat B, Omari M. Uterine and tubal anatomical abnormalities in infertile women: Diagnosis with routine hysterosalpingography prior to selective laparoscopy. SA J Radiol. 2011;15(4):121-122. https://doi.org/10.4102/sajr.v15i4.354

13. Panti AA, Sununu YT. The profile of infertility in a teaching hospital in North West Nigeria. Sahel Med J. 2014;17(1):7-11. https://doi.org/10.4103/1118-8561.129145.

14. Chen WJ, Walker N. Fertility of HIV-infected women: Insights from demographic and health surveys. Sex Transm Infect. 2010;86(2):22-27. https://doi.org/10.1136/ sti.2010.043620

15. Khetmalas SM, Kathaley MH. A study evaluation of tubal factors of infertility by hysterosalpingography and diagnostic laparoscopy. MVP J Med Sci. 2016;3(1):11-17. https://doi.org/10.18311/mvpjms/2016/v3/i1/722

16. Okafor $\mathrm{CO}$, Okafor $\mathrm{Cl}$, Okpala OC, Umeh E. The pattern of hysterosalpingography findings in women being investigated for infertility in Nnewi, Nigeria. Niger J Clin Pract. 2010;13(3):264-267.

17. Favot I, Ngalula J, Mgalla Z, Klokke AH, Gumodaka B, Boerma JT. HIV infection and sexual behavior among women with infertility in TANZIANIA: A hospitalbased study. Int J Epidemiol. 1997;26(2):414-419. https://doi.org/10.1093/ ije/26.2.414

18. Statistics South Africa. Midyear population estimates 2017 [homepage on the Internet]. Department: Statistics South Africa Republic of South Africa. [cited 2017 Dec. 12] Available from: https://www.stassa.gov.za

19. Nwankwo NC, Akani $\mathrm{Cl}$. Pattern of hysterosalpingography in patients with infertility in Port Harcourt. West Afr J Radiol. 2005;12(1);15-19. https://doi.org/ 10.4314/wajr.v12i1.34200

20. Elsie KM, Rosemary KB, Structural finding at hysterosalpingography in patients with infertility at private clinics in Kampala, Uganda. Afr Health Sci. 2004:4(3): 178-181.

21. Onwuchekwa CR, Oriji VK. Hysterosalpingography pattern of infertility in women of reproductive age. J Hum Reprod Sci. 2017;10(3):178-184. https://doi.org/ 10.4103/jhrs.JHRS_121_16 